\title{
Measuring educational needs among patients with rheumatoid arthritis using the Dutch version of the Educational Needs Assessment Tool (DENAT)
}

\author{
Jorit J. L. Meesters • Theodora P. M. Vliet Vlieland • \\ Jackie Hill • Mwidimi E. Ndosi
}

Received: 2 February 2009/Revised: 17 April 2009 /Accepted: 24 April 2009/Published online: 16 May 2009

(C) The Author(s) 2009. This article is published with open access at Springerlink.com

\begin{abstract}
The Educational Needs Assessment Tool (ENAT) was developed in the United Kingdom (UK) to systematically assess the educational needs of patients with arthritis. The aim of the present study was to describe the educational needs of Dutch patients with rheumatoid arthritis (RA) by using the Dutch version of the ENAT (DENAT). The original UK version of the ENAT, comprising 39 items grouped into seven domains, was translated into Dutch according to international guidelines for cross-cultural translation and adaptation. The DENAT was then sent to a random sample of 319 RA patients registered at the outpatient clinic of a university hospital. For each domain (score range 1-5, equalling low-high educational needs), a median score with the inter-quartile range was computed. The Kruskal-Wallis test was used to determine possible associations between educational needs and age, disease duration, gender and educational background. The response rate was 165 out of 319 (52\%). The median educational needs scores were 2.5 for "managing pain", 3.0 for "movement", 2.0 for "feelings",
\end{abstract}

J. J. L. Meesters · T. P. M. Vliet Vlieland

Department of Rheumatology, Leiden University Medical Center, Leiden, the Netherlands

\section{J. J. L. Meesters $(\bowtie)$}

Department of Physical Therapy (Postal zone H0-Q),

Leiden University Medical Center,

PO Box 96002300 RC, Leiden, the Netherlands

e-mail: J.J.L.Meesters@lumc.nl

T. P. M. Vliet Vlieland

Department of Orthopaedics, Leiden University Medical Center,

Leiden, the Netherlands

J. Hill • M. E. Ndosi

Academic and Clinical Unit for Musculoskeletal Nursing,

University of Leeds,

Leeds, UK
4.0 for "arthritis process", 4.0 for "treatments from health professionals", 3.5 for "self-help measures" and 2.5 for "support systems". Lower age and shorter disease duration were associated with more educational needs in the domain "support systems". In addition, younger patients had more educational needs regarding managing pain and feelings than older patients. There were no associations between gender or educational background and educational needs. The DENAT has demonstrated its ability to identify individual educational needs of Dutch patients with RA. The lower age and shorter disease duration were associated with more educational needs. The practical applicability of the DENAT needs further research.

Keywords Allied health professionals . Consumer health information · Health knowledge .

Needs assessment $\cdot$ Patient education $\cdot$ Rheumatoid arthritis

\section{Introduction}

Despite important developments in the medical treatment of rheumatoid arthritis (RA), this disease has a major impact on important life areas of many patients [1]. Over the past two decades, a growing emphasis has been put on arthritis self management strategies to help patients with RA cope with the consequences of the disease. In order to manage the disease on a day-to-day basis, patients need a formal body of knowledge and skills [2]. Individual, group-wise and Internet-based educational programmes have proven to be effective in improving self-efficacy, as well as in diminishing pain and disability [3-5] in patients with RA. However, recent studies show limited long-term effects of standardised educational interventions, and the provision of more patientcentred and tailor-made programmes is advocated [6-9]. 
Tailor-made patient education requires good insight into the individual's educational needs. Until recently, no instruments were available to systematically assess RA patients' educational needs. This meant that the provision of educational strategies that were timely and relevant to the individual patient was difficult, and the planning of educational interventions on the group level more so. Lately, the Arthritis Educational Needs Assessment Tool (ENAT) was developed [10] in the UK. Its early face validity was assessed among arthritis patients, and its test-retest reliability demonstrated a good repeatability of the instrument $\left(r_{\mathrm{s}}=0.82 ; \mathrm{ICC}=0.87\right)$ [10]. The ENAT was later validated in patients with RA by Rasch analysis and found to be a robust tool [11].

Until now, little has been known about the educational needs of RA patients in the Netherlands. The aim of this paper is to describe the educational needs of Dutch patients with RA by using a translated Dutch version of the ENAT (DENAT).

\section{Methods}

The original ENAT is a patient-completed questionnaire, comprising 39 items, grouped into seven domains: managing pain (seven items), movement (five items), feelings (four items), arthritis process (seven items), treatments (seven items), self-help measures (six items) and support systems (four items). Within each domain, patients are asked to rate the question "How important is it for you to know more about..." for all items in that domain. The patients rate their responses using five-point Likert scales with the descriptors: "not at all important" $=1$, "fairly important" $=2$, “a little important" $=3$, "very important" $=4$ and "extremely important" $=5$. In every domain, the scores of the various items are summed and divided by the number of items in that domain, resulting in all domain scores ranging from one to five. If a single patient missed one or more items in a domain, the patient was not included in the analysis of that specific domain. Examples of statements in the DENAT are the following: "Ways to deal with moods and depression" (domain "feelings") and "Exercises I should be doing" (domain "self-help measures").

The ENAT was translated into Dutch using an established translation methodology [12], which comprised the following stages: An initial forward translation was undertaken by two independent bilingual translators (CD and IB) whose mother tongue was the target language (Dutch). A synthesis of these translations was mediated by a third person (TV). Then, a back-translation was produced by an independent assessor (PL and FK), translating the newly translated ENAT back into English. Finally, an expert committee including a methodologist (TV), a health professional $(\mathrm{JV})$, all the previously mentioned translators and a translation recorder $(\mathrm{JH})$ agreed upon the final version for field testing. The same process has been used successfully to translate the ENAT into Finnish [13], Norwegian [14], Spanish [15] and Swedish [16]. In the subsequent field testing, 30 RA patients completed the DENAT and were interviewed to assess their understanding of the questions. The field testing resulted in some minor changes of the wording.

In October 2006, a random sample of 319 patients with RA [283 women (89\%) and 36 men (11\%), median age 68 years] was selected from the total population of 1,054 RA patients visiting the outpatient clinic of the Department of Rheumatology at the Leiden University Medical Center (LUMC) in Leiden, the Netherlands, during a period of 12 months. All patients were given a number using a Microsoft Excel random digit generator, and the highest 350 numbers were selected. After verification of the diagnosis in the medical record and a check of the national population register, 319 patients remained.

The DENAT and a questionnaire on age, gender, selfreported disease duration (years) and educational background were sent to these patients to complete at home and return to the LUMC in a pre-stamped envelope via postal mail. Educational background was defined as highest formal education achievement and categorised as primary (up to and including lower technical and vocational training), secondary (up to and including secondary technical and vocational training) and tertiary (up to and including higher technical and vocational training and university).

The study was judged to be non-medical research according to the Medical Research Involving Human Subjects Act by the Medical Ethics Review Committee of the LUMC. For this reason, it was not necessary to obtain individual informed consent (the participants were free to either fill in the questionnaire or not).

The questionnaires were analysed descriptively using the Statistical Package for the Social Sciences (SPSS 15.0 for Windows, Chicago, IL, USA). Because all items were measured at an ordinal level, for each domain, a median score with the inter-quartile range (IQR) was computed. The educational needs were then compared between patient groups, categorised by age, disease duration, gender and educational background. The Kruskal-Wallis test ( $H$ value) was used to determine significant differences between patient groups.

\section{Results}

Population characteristics

The questionnaire was returned by 165 patients (response rate $=52 \%$ ) with $\mathrm{RA}$, including 146 females $(88.5 \%)$ and 19 
males (11.5\%), with a median age of 68 years (IQR 55-77) and a median disease duration of 13 years (IQR 7-21). Based on their educational background, the numbers of patients with primary education were $29(18 \%)$, with secondary education $99(60 \%)$ and with tertiary education $35(21 \%)$, and two (1\%) had unknown educational backgrounds.

Educational needs

The internal consistency of the 39 DENAT items (Cronbach's Alpha reliability) was 0.97 . Table 1 shows the educational needs of the patients. The median scores within the domains "arthritis process", "treatments from health professionals" and "self-help measures" were the highest $(\geq 3.5)$, whereas the scores for "managing pain", "movement", "support systems" and "feelings" were lower $(\leq 3.0)$.

Associations in educational needs with age, disease duration, gender and education

Table 2 shows comparisons of ENAT domain scores between subgroups of patients. With the sample divided at the median age (68 years), it was found that older patients expressed significantly less educational need than younger patients regarding managing pain, feelings and support systems. Based on the cut-off point of the median disease duration (13 years), patients with longer disease durations had significantly more educational needs within the domain support systems than those with shorter disease duration. There were no statistically significant differences in the ENAT domain scores between men and women or between patients with different educational backgrounds.

\section{Discussion}

This cross-sectional study among a random sample of patients with RA in the Netherlands shows that there is a considerable educational need, particularly with respect to arthritis process, treatments from health professionals and self-help measures. Less importance was attributed to the need for education in the domains managing pain and movement. These findings are in agreement with previous studies among RA patients [17] and patients with various rheumatic diseases $[10,18,19]$ which demonstrate a high need for information on disease and medical care. The educational needs on feelings were rated as "a little important", despite the relatively high prevalence of anxiety and depression in patients with RA in general [20]. However, our results are in concordance with a recent study showing that patients with RA are the least interested in information regarding dealing with emotions [18].

In our study, younger patients had a higher need for education within the domains managing pain, feelings and support systems than older patients. The inverse association between age and information need is in line with the findings of other studies in the field of patient information and education [17, 18, 21].

Patients with longer disease duration showed higher educational needs on support systems, which is possibly related to more disease-related disability. However, these results should be interpreted with care. The division of the sample in two categories ( $<$ or $>13$ years) for disease duration was merely based on the sample distribution. In addition, disease duration was self-reported, which may have influenced reliability.

No significant association between gender and educational needs was observed in the present study, whereas other studies showed significantly higher needs for information [17] and education [10] in women than in men. Our results, however, point in the same direction, and the lack of significance could probably be explained by the fact that, in our sample, men were relatively underrepresented (male/ female ratio $1: 8$ ).

Our study showed no significant differences in educational needs among patients with different educational backgrounds. In literature, conflicting results regarding the association between educational level and educational needs among patients with arthritis have been reported $[10,17]$.

This study had a number of limitations. First, the sample was selected from only one hospital, the response was $52 \%$, men were relatively underrepresented and the median age of the sample was relatively high (68 years), so the generalizability of the results may be limited. In the present study, we did not measure if the need for information was related to the actual level of knowledge of the patients. Previous research by Mäkeläinen [22] in RA patients has demonstrated that younger and female patients obtained higher scores than older and male counterparts on the

Table 1 Educational need scores (range from one to five, equalling low-high educational needs) according to the DENAT completed in 165 Dutch patients with RA

\begin{tabular}{llllllll}
\hline & Managing pain & Movement & Feelings & Arthritis process & Treatments from health professionals & Self-help measures & Support systems \\
\hline Median & 2.5 & 3.0 & 2.0 & 4.0 & 4.0 & 3.5 & 2.5 \\
IQR & $1-4$ & $1-4$ & $1-4$ & $3-5$ & $3-5$ & $2-4$ & $1-3$ \\
\hline
\end{tabular}




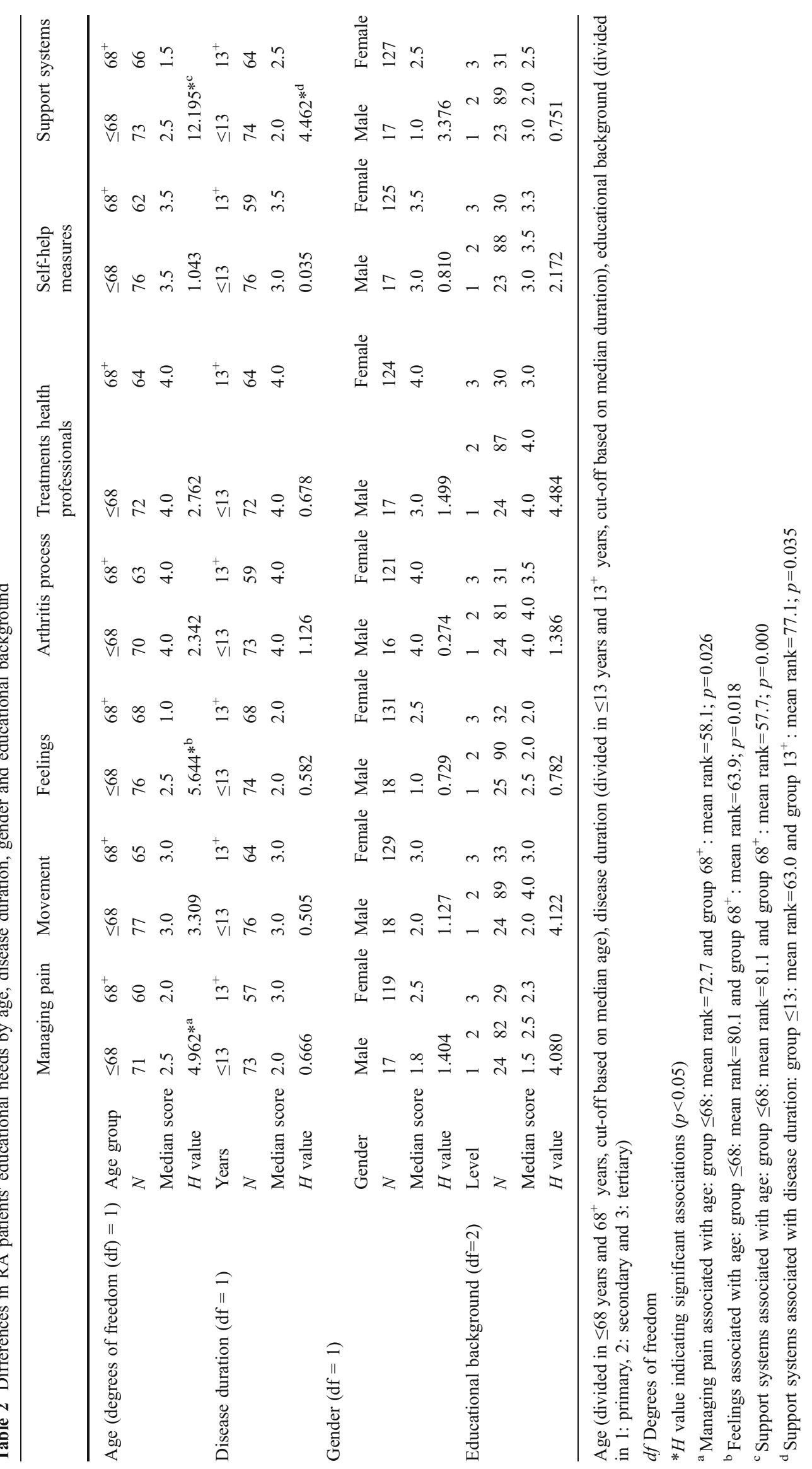


Patient Knowledge Questionnaire, which was designed to assess patients' general knowledge of RA and its treatments [23]. As younger people and women also appear to have the highest educational needs, measuring both the educational needs and the actual level of knowledge is probably to be preferred in the design of an educational programme for RA patients.

To conclude, the results of this study have shown that educational needs among Dutch-speaking RA patients are high. The findings underline the importance for patient education in RA as an integrated part of standard rheumatologic care. Given the emphasis on patient-centred health care [24] and tailor-made educational programmes $[8,9]$, the identification of individual educational needs becomes imperative. So far, the DENAT is the only objective tool to identify educational needs among Dutchspeaking patients with RA. Further research into the usefulness of the DENAT in daily clinical practice, and its application in other rheumatic diseases is needed. Moreover, a cross-cultural comparison of educational needs across countries [13-16] would be interesting. This collaborative work is currently underway, involving all countries which participated in the translation of the ENAT.

Acknowledgements We would like to thank C. Donner, I. de Boer, P. Longbottom, F. Kurreeman, J. Woodburn, J. Verhoef and A. Jackson for their participation in the translation procedure. The translation procedure was financially supported by a EULAR Health Professionals Research Grant (project "Adaptation of the Educational Needs Assessment Tool for use in 4 European Countries". Project team leader: J. Hill).

Disclosures None

Open Access This article is distributed under the terms of the Creative Commons Attribution Noncommercial License which permits any noncommercial use, distribution, and reproduction in any medium, provided the original author(s) and source are credited.

\section{References}

1. Isenberg DA (2004) Oxford textbook of rheumatology. Oxford University Press, Oxford

2. Taal E, Rasker JJ, Wiegman O (1996) Patient education and selfmanagement in the rheumatic diseases: a self-efficacy approach. Arthritis Care Res 9:229-238

3. Riemsma RP, Kirwan JR, Taal E et al (2003) Patient education for adults with rheumatoid arthritis. Cochrane Database Syst Rev 2: CD003688

4. Riemsma RP, Taal E, Rasker JJ (2003) Group education for patients with rheumatoid arthritis and their partners. Arthritis Rheum 49:556-566

5. Lorig KR, Ritter PL, Laurent DD et al (2004) Long-term randomized controlled trials of tailored-print and small-group arthritis self-management interventions. Med Care 42:346-354
6. Solomon DH, Warsi A, Brown-Stevenson T et al (2002) Does self-management education benefit all populations with arthritis? A randomized controlled trial in a primary care physician network. J Rheumatol 29:362-368

7. Li LC (2007) If knowledge is power, why don't rheumatoid arthritis education programs show better outcomes? J Rheumatol 34:1645-1646

8. Coulter A, Ellins J (2007) Effectiveness of strategies for informing, educating, and involving patients. BMJ 335:24-27

9. Bode C, Taal E, Emons PA et al (2008) Limited results of group self-management education for rheumatoid arthritis patients and their partners: explanations from the patient perspective. Clin Rheumatol 27:1523-1528

10. Hardware B, Lacey E, Shewan J (2004) Towards the development of a tool to assess educational needs in patients with arthritis. Clin Eff Nurs 8:111-117

11. Hill J, Tennant A, Adebajo A (2004) Further development of an educational needs assessment tool (ENAT) for patients with rheumatoid arthritis. Arthritis Rheum 50:S274-S275

12. Beaton DE, Bombardier C, Guillemin F et al (2000) Guidelines for the process of cross-cultural adaptation of self-report measures. Spine 25:3186-3191

13 Kukkurainen M, Heinonen M, Karppinen L et al (2008) Evaluation of educational needs among patients with RA using the Finnish version of ENAT. Ann Rheum Dis 67(Suppl II):584

14 Zangi HA, Hamnes B, Ndosi M et al (2008) Assessment of RA patients' educational needs by use of the Norwegian version of the ENAT (NORENAT). Ann Rheum Dis 67(Suppl II):670

15 de la Torre-Aboki J, Carbonell-Jorda A, Martinez-Alberola N et al (2008) Evaluation of educational needs among patients with RA using the Spanish version of the ENAT (SPENAT). Ann Rheum Dis 67(Suppl II):667

16 Bergsten U, Arvidsson B, Bergman S et al (2008) Evaluation of educational needs among patients with RA using the Swedish version of ENAT (SwENAT). Ann Rheum Dis 67(Suppl II):666

17. Neame R, Hammond A, Deighton C (2005) Need for information and for involvement in decision making among patients with rheumatoid arthritis: a questionnaire survey. Arthritis Rheum 53:249-255

18. Adab P, Rankin EC, Witney AG et al (2004) Use of a corporate needs assessment to define the information requirements of an arthritis resource centre in Birmingham: comparison of patients' and professionals' views. Rheumatology (Oxford) 43:1513-1518

19. Neville C, Fortin PR, Fitzcharles MA et al (1999) The needs of patients with arthritis: the patient's perspective. Arthritis Care Res 12:85-95

20. Isik A, Koca SS, Ozturk A et al (2007) Anxiety and depression in patients with rheumatoid arthritis. Clin Rheumatol 26:872-878

21. Gordon MM, Capell HA, Madhok R (2002) The use of the Internet as a resource for health information among patients attending a rheumatology clinic. Rheumatology (Oxford) 41:1402-1405

22. Mäkeläinen P, Vehviläinen-Julkunen K, Pietilä AM (2009) Rheumatoid arthritis patients' knowledge of the disease and its treatments: A descriptive study. Musculoskelet Care 7:31-44

23. Hill J, Bird HA, Hopkins R et al (1991) The development and use of Patient Knowledge Questionnaire in rheumatoid arthritis. Br J Rheumatol 30:45-49

24. Kjeken I, Dagfinrud H, Mowinckel P et al (2006) Rheumatology care: Involvement in medical decisions, received information, satisfaction with care, and unmet health care needs in patients with rheumatoid arthritis and ankylosing spondylitis. Arthritis Rheum $55: 394-401$ 